\title{
Comparison between clinical significance of serum proinflammatory proteins (IL-6 and CRP) and classic tumor markers (CEA and CA 19-9) in gastric cancer
}

\author{
Marta Lukaszewicz-Zając • Barbara Mroczko • \\ Mariusz Gryko • Bogusław Kędra • \\ Maciej Szmitkowski
}

Received: 5 August 2010/Accepted: 27 September 2010/Published online: 12 October 2010

(C) The Author(s) 2010. This article is published with open access at Springerlink.com

\begin{abstract}
Gastric cancer (GC) is a second most common cause of cancer-related death and represents an inflammation-driven malignancy. It has been suggested that interleukin 6 (IL-6) and C-reactive protein (CRP) play a potential role in the growth and progression of GC. The aim of the present study was to compare clinical significance of IL-6 and CRP with classic tumor markers-carcinoembryonic antigen (CEA) and carbohydrate antigen (CA 19-9) in GC patients. The study included 92 patients with GC and 70 healthy subjects. The serum concentrations of IL-6, CEA and CA 19-9 were determined using immunoenzyme assays, whereas CRP using immunoturbidimetric method. We defined the diagnostic criteria and prognostic value for proteins tested. In GC patients, the serum concentrations of all the proteins tested were significantly higher than in healthy subjects. The IL-6, CEA and CA 19-9 levels correlated with nodal metastases, while CRP with tumor stage, gastric wall invasion, presence of nodal and distant metastases. Diagnostic sensitivity of IL-6 was higher $(85 \%)$ than those of other markers (CRP 66\%, CA 19-9 34\%, CEA 22\%) and increased in combined use with CRP or CEA (88\%). The area under ROC curve for IL-6 was larger than those of CRP and classic tumor markers (CEA and CA 19-9). None of the proteins tested was independent prognostic factor for the survival of GC patients. Our findings indicate better usefulness of serum
\end{abstract}

M. Łukaszewicz-Zając $(\bowtie) \cdot$ B. Mroczko · M. Szmitkowski Department of Biochemical Diagnostics, Medical University, Waszyngtona 15 a, 15-269 Białystok, Poland

e-mail: marta.lukaszewicz-zajac@umwb.edu.pl

M. Gryko · B. Kędra

Second Department of General Surgery, Medical University, Białystok, Poland proinflammatory proteins-IL-6 and CRP than classic tumor markers-CEA and CA 19-9 in the diagnosis of GC.

Keywords CRP - Gastric cancer - IL-6 - Tumor marker

\section{Introduction}

Gastric cancer (GC) remains a second most common cause of cancer-related death worldwide and the predicted incidence for 2010 is over 1 million [1, 2]. Several factors are suspected to play a role in the development of GC, including effects of diet, intake of smoked, exogenous chemicals, genetic factors or infectious agents [2, 3]. Clinical and epidemiological studies have shown the link between gastric cancer and chronic inflammation, thus pathogenesis of GC represents an inflammation-driven malignancy $[2,4]$. The potential significance of interleukin 6 (IL-6) and C-reactive protein (CRP) has been suggested in the growth and progression of many malignancies, including GC $[5,6]$.

IL-6 is a pleiotropic inflammatory cytokine that plays conflicting role into tumor cells [7-9]. It may promote the killing of cancer cells by the stimulation of antitumor activity of macrophages and prevents apoptosis of neutrophils $[7,8]$. However, IL-6 may be also produced by tumor cells, including GC cell lines [7, 10]. It has been suggested that the IL-6 pathway is one of the mechanism that link inflammation and angiogenesis to malignancy [5]. This cytokine is able to induce the expression of vascular endothelial growth factor (VEGF) [11]. In addition, IL-6 activates the Rho protein, which is associated with cell-cell adhesion and invasion in cancer [12]. Some authors have shown the expression of this cytokine and its receptor in GC tissue $[10,13,14]$. These findings suggested that IL-6 
may act as an autocrine or paracrine growth factor for gastric carcinomas and play a crucial role in the pathogenesis of GC [10, 13-15]. C-reactive protein is produced by hepatocytes as a response to inflammatory cytokines, such as IL-6, during tissues damage induced by infection, trauma or cancer [9]. Some authors have suggested that malignancy induced CRP production in hepatocytes [16]. Recently, CRP has been associated with the progression of disease in many types of cancers, including GC [5]. Increased concentrations of IL-6 and CRP were detected in the blood of patients with colorectal [17], lung [18] and gastric cancer [3, 5, 19, 20]. It has been shown that IL-6 and CRP levels correlated with clinicopathological features of GC, such as tumor stage, depth of tumor invasion and the presence of lymph node metastasis [3, 5, 7, 19, 20]. Some authors have also suggested the potential significance of IL-6 and CRP as prognostic factors for the survival of GC patients $[5,7,15,19]$. However, according to our knowledge, this is the first study assessing diagnostic criteria for IL-6 and CRP in the sera of GC patients, especially in comparison with classic tumor markerscarcinoembryonic antigen (CEA) and carbohydrate antigen (CA 19-9).

Therefore, the aim of the present study was to compare the clinical significance of serum IL-6 and CRP with classic tumor markers (CEA and CA 19-9) in the diagnosis of GC patients based on the diagnostic criteria, such as diagnostic sensitivity and specificity, positive and negative predictive values as well as ROC curve. Moreover, we assessed the concentrations of IL-6, CRP and classic tumor markers in the sera of GC patients in relation to clinicopathological features of cancer, including tumor stage, depth of tumor invasion, the presence of lymph node and distant metastases as well as resectability of tumor and patients' survival.

\section{Materials and methods}

Patients

The study included 92 GC patients ( 27 women and 65 men, aged 28-84 years) diagnosed by the Oncology Group and operated on by the Second General Medicine Department of the Medical University of Białystok. The control group comprised 70 healthy volunteers (53 women and 15 men, aged 20-69 years). The microscopic examination of material obtained during biopsy and/or surgery was used in the clinical diagnosis of GC patients. Seventy-two GC patients underwent surgical tumor resection, while 20 patients had nonresectable tumors. The staging of cancer was based on a routine histopathological analysis and clinical assessment, according to TNM (tumor-nodulus-metastases) classification. Tumors were classified proposed by the 5 th International Union Against Cancer (UICC) [21].

For statistical analysis, GC patients were divided into three groups: 19 cancer patients in stage I + II, 27 patients in stage III, and 46 patients in stage IV. They were also subdivided into: three groups depending on gastric wall invasion ( $11+\mathrm{T} 2$, T3 and T4), four groups depending on nodal involvement (N0, N1, N2 and N3) and two groups depending on the presence of distant metastasis (M0 and M1). Thirty-six patients died of GC, whereas 50 patients survived. The number of patients in the analyzed subgroups is shown in Table 1. The study was approved by the Local

Table 1 Characteristic of gastric cancer patients

\begin{tabular}{|c|c|}
\hline Tested group & Number of patients \\
\hline Gastric cancer patients & 92 \\
\hline \multicolumn{2}{|l|}{ Gender } \\
\hline Female & 27 \\
\hline Male & 65 \\
\hline \multicolumn{2}{|l|}{ Age } \\
\hline$\geq 65$ years & 45 \\
\hline$<65$ years & 47 \\
\hline \multicolumn{2}{|l|}{ Tumor stage } \\
\hline 1 & 12 \\
\hline 2 & 7 \\
\hline $1+2$ & 19 \\
\hline 3 & 27 \\
\hline 4 & 46 \\
\hline \multicolumn{2}{|l|}{ Tumor size } \\
\hline $\mathrm{T} 1$ & 7 \\
\hline $\mathrm{T} 2$ & 8 \\
\hline $\mathrm{T} 1+\mathrm{T} 2$ & 15 \\
\hline $\mathrm{T} 3$ & 41 \\
\hline $\mathrm{T} 4$ & 36 \\
\hline \multicolumn{2}{|l|}{ Nodal metastases } \\
\hline No & 19 \\
\hline N1 & 12 \\
\hline $\mathrm{N} 2$ & 22 \\
\hline N3 & 39 \\
\hline \multicolumn{2}{|l|}{ Distant metastases } \\
\hline M0 & 53 \\
\hline M1 & 39 \\
\hline \multicolumn{2}{|l|}{ Resectability of tumor } \\
\hline Resectable & 72 \\
\hline Nonresectable & 20 \\
\hline \multicolumn{2}{|l|}{ Survival of patients } \\
\hline Died & 36 \\
\hline Alive & 50 \\
\hline Data not available & 6 \\
\hline
\end{tabular}


Ethics Committee, and all the patients gave informed consent.

Biochemical analyses

Blood samples from all the patients were drawn before treatment (Sarstedt, Nümbrecht, Germany), and then sera were separated within $1 \mathrm{~h}$ after blood collection and stored at $-80^{\circ} \mathrm{C}$ until analysis.

Serum IL-6 concentrations were measured using an enzyme-linked immunosorbent assay kits (ELISA) (R\&D Systems, Abingdon, UK) according to the manufacturer's instructions. The intra-assay coefficient of variation (CV\%) is reported by the manufacturer to be $4.2 \%$ at a mean concentration of $16.8 \mathrm{pg} / \mathrm{mL}$ with $\mathrm{SD}=0.7 \mathrm{pg} / \mathrm{mL}$. Concentrations of CRP in the sera were determined using an immunoturbidimetric Protiline ${ }^{\circledR}$ CRP assay kits (bioMerieux, Lyon, France) in accordance with the manufacturer's instructions. The intra-assay $\mathrm{CV} \%$ reported by the manufacturer is $2.49 \%$ at a mean concentration of $10 \mathrm{mg} / \mathrm{L}$.

Serum concentrations of CEA and CA 19-9 in the patients and healthy controls were measured using a microparticle enzyme immunoassay kits (MEIA) (Abbott, Chicago, IL, USA). The intra-assay CV\% for CEA as reported by the manufacturer of the assay kits is $4.9 \%$ at a mean concentration of $2.2 \mathrm{ng} / \mathrm{mL}$ with $\mathrm{SD}$ of $0.11 \mathrm{ng} / \mathrm{mL}$, and the intra-assay CV\% for CA $19-9$ is $4.7 \%$ at a mean concentration of $38.2 \mathrm{U} / \mathrm{mL}$ with $\mathrm{SD}=1.80 \mathrm{U} / \mathrm{mL}$.

The reference cut-off values for CEA (4.0 ng/mL) and CA $19-9(30.0 \mathrm{U} / \mathrm{mL})$ (the 95 th percentile) were established previously in our department [17]. The cut-off values for IL-6 (2.46 pg/mL) and CRP (5.2 mg/L) correspond to the highest accuracy (minimal false-negative and falsepositive results).

\section{Statistical analysis}

The values of IL-6, CRP, CEA and CA 19-9 levels did not follow a normal distribution in preliminary statistical analysis $\left(\chi^{2}\right.$-test). The comparisons between two groups were performed by the Mann-Whitney U-test and for three groups or more, the one-way ANOVA Kruskal-Wallis test was used. Data are presented as the median and range. The differences were considered statically significant when $P<0.05$. The Kaplan and Meier method was used for the calculation of the survival curves. The log-rank test for univariate analyses of survival and the Cox proportional hazards model for multivariate analyses were employed. In addition, we calculated the area under the receiver operating characteristic (ROC) curve (AUC) for the IL-6, CRP and classic tumor markers. Statistical analysis was performed using the STATISTICA 5.1 PL program (StatSoft
Inc., Tulsa, OK, USA). Diagnostic criteria were calculated using MedCalc statistical software (Mariakerke, Belgium) and Microsoft Office Excel.

\section{Results}

Tables 2 and 3 present the median and range of serum concentrations of IL-6, CRP and classic tumor markers (CEA and CA 19-9) in GC patients and in healthy subjects (control group). In GC patients, the concentrations of all the proteins tested were found to be statistically higher when compared with healthy subjects $(P<0.001)$. The serum concentrations of IL-6, CRP and tumor markers in GC patients increased with tumor stage and were the highest in patients with stage IV, although statistically significant differences were found between stage IV and II for CRP ( $P=0.025)$ (Table 2$)$ and between stage IV, III and II for CA 19-9 (0.028) (Table 3).

If we consider the concentrations of IL-6, CRP and classic tumor markers in relation to clinicopathological variables of tumor, such as gastric wall invasion ( $\mathrm{T}$ factor), the serum levels of all the proteins measured are highest in patients in T4 subgroup. The differences between $\mathrm{T} 1+2$, T3 and T4 subgroups are significant for serum CRP levels and between $\mathrm{T} 1+2$ and T4 for CA 19-9. Serum levels of all the proteins tested varied according to nodal metastases ( $\mathrm{N}$ factor) and were the highest in the N3 subgroup. The CRP and CEA concentrations were significantly higher in N3 subgroup than in N0 and N2 patients (respectively, $P=0.020$ and $P=0.046$ ), the IL-6 levels were significantly higher in N3 patients when compared with N2 tumors (0.040), whereas CA 19-9 concentrations were significantly different in $\mathrm{N} 3$ and $\mathrm{N} 1$ subgroups than in N0 patients (0.001). The serum concentrations of all the proteins tested correlated with the presence of distant metastasis ( $\mathrm{M}$ factor) and were higher in M1 subgroup when compared with patients without distant metastasis. However, the differences were found to be significant only for CRP levels (0.026). Moreover, serum levels of CRP, IL-6 and CA 19-9 were higher in patients with nonresectable tumors in comparison with those with the resectable ones, although these differences were not significant.

The relationship between survival of GC patients and serum concentrations of proteins tested was assessed using the Kaplan-Meier method. The univariate log-rank analysis showed that the tumor stage $(P=0.001)$, tumor size $(P=0.003)$, the presence of nodal $(P=0.001)$ and distant metastases $(P=0.001)$, tumor resectability $(P=0.001)$ as well as the serum levels of CEA and CA 19-9 $(\mathrm{p}=0.005)$ were the significant factors affecting overall survival (Table 4). Multivariate regression analysis with the Cox's proportional hazards model revealed that only tumor stage 
Table 2 Serum concentrations of CRP and IL-6 in gastric cancer patients

\begin{tabular}{|c|c|c|c|c|c|c|c|c|c|}
\hline \multirow[b]{3}{*}{ Gastric cancer patients } & \multirow{3}{*}{$\begin{array}{l}N \\
92\end{array}$} & \multicolumn{4}{|c|}{ CRP (mg/L) } & \multicolumn{4}{|c|}{ IL-6 (pg/mL) } \\
\hline & & \multirow{2}{*}{$\frac{\text { Median }}{11.1^{\mathrm{a}}}$} & \multicolumn{2}{|l|}{ Range } & \multirow{2}{*}{$\begin{array}{l}P \\
<0.001\end{array}$} & \multirow{2}{*}{$\frac{\text { Median }}{8.04^{\mathrm{a}}}$} & \multicolumn{2}{|l|}{ Range } & \multirow{2}{*}{$\frac{P}{<0.001}$} \\
\hline & & & 1.4 & 238.7 & & & 0.00 & 201.97 & \\
\hline Control group & 70 & 5.0 & 0.1 & 8.9 & & 1.32 & 0.00 & 26.71 & \\
\hline \multicolumn{10}{|l|}{ Tumor stage } \\
\hline II & 19 & $5.0^{\mathrm{a}}$ & 1.7 & 59.3 & 0.025 & $4.69^{\mathrm{a}}$ & 0.00 & 46.24 & 0.451 \\
\hline III & 27 & $10.4^{\mathrm{a}}$ & 1.7 & 145.9 & & $6.92^{\mathrm{a}}$ & 1.27 & 69.20 & \\
\hline IV & 46 & $15.3^{\mathrm{a}, \mathrm{b}}$ & 1.4 & 238.7 & & $9.09^{\mathrm{a}}$ & 1.12 & 201.97 & \\
\hline \multicolumn{10}{|l|}{ Gastric wall invasion } \\
\hline $\mathrm{T} 1+\mathrm{T} 2$ & 15 & $5.0^{\mathrm{a}, \mathrm{c}}$ & 1.7 & 43.5 & 0.005 & $5.13^{\mathrm{a}}$ & 0.40 & 46.24 & 0.283 \\
\hline $\mathrm{T} 3$ & 41 & $10.2^{\mathrm{a}, \mathrm{c}}$ & 1.4 & 145.9 & & $5.88^{\mathrm{a}}$ & 0.00 & 69.20 & \\
\hline $\mathrm{T} 4$ & 36 & $19.2^{\mathrm{a}}$ & 1.9 & 238.7 & & $9.53^{\mathrm{a}}$ & 1.42 & 201.97 & \\
\hline \multicolumn{10}{|l|}{ Nodal metastases } \\
\hline No & 19 & $8.5^{\mathrm{a}}$ & 1.7 & 59.3 & 0.020 & $5.13^{\mathrm{a}}$ & 0.00 & 46.24 & 0.040 \\
\hline N1 & 12 & $7.9^{\mathrm{a}}$ & 1.7 & 60.4 & & $5.07^{\mathrm{a}}$ & 1.44 & 69.20 & \\
\hline N2 & 22 & $7.3^{\mathrm{a}}$ & 3.0 & 55.5 & & $4.54^{\mathrm{a}}$ & 1.27 & 45.77 & \\
\hline N3 & 39 & $16.8^{\mathrm{a}, \mathrm{d}, \mathrm{e}}$ & 1.4 & 238.7 & & $11.26^{\mathrm{a}, \mathrm{e}}$ & 2.01 & 201.97 & \\
\hline \multicolumn{10}{|l|}{ Distant metastases } \\
\hline M0 & 53 & $7.8^{\mathrm{a}}$ & 1.7 & 145.9 & 0.026 & $5.44^{\mathrm{a}}$ & 0.00 & 69.20 & 0.227 \\
\hline M1 & 39 & $16.1^{\mathrm{a}, \mathrm{f}}$ & 1.4 & 238.7 & & $9.31^{\mathrm{a}}$ & 1.12 & 201.97 & \\
\hline \multicolumn{10}{|l|}{ Resectability of tumor } \\
\hline Resectable & 72 & $10.3^{\mathrm{a}}$ & 1.4 & 238.7 & 0.134 & $6.7^{\mathrm{a}}$ & 0.00 & 93.90 & 0.339 \\
\hline Nonresectable & 20 & $17.9^{\mathrm{a}}$ & 1.9 & 90.1 & & $9.75^{\mathrm{a}}$ & 2.01 & 201.97 & \\
\hline \multicolumn{10}{|l|}{ Survival of patients } \\
\hline Alive & 50 & $10.3^{\mathrm{a}}$ & 1.7 & 145.9 & 0.187 & $5.37^{\mathrm{a}}$ & 0.00 & 69.20 & 0.360 \\
\hline Died & 36 & $12.2^{\mathrm{a}}$ & 1.4 & 238.7 & & $9.09^{\mathrm{a}}$ & 1.12 & 93.90 & \\
\hline
\end{tabular}

${ }^{a}$ Statistically significant compared to control group

b Statistically significant compared to stage II

c Statistically significant compared to T4 subgroup

d Statistically significant compared to N0 subgroup

e Statistically significant compared to N2 subgroup

${ }^{\mathrm{f}}$ Statistically significant compared to M0 subgroup

$(P=0.024)$, tumor resectability $(P=0.013)$ and the presence of distant metastasis $(P=0.019)$ were independent prognostic factors for the survival of GC patients.

The percentage of increased concentrations (diagnostic sensitivity) of proteins tested is presented in Fig. 1. The diagnostic sensitivity of IL-6 $(85 \%)$ was higher than those of CRP (66\%) and much higher than classic tumor markers-CEA (22\%) and CA 19-9 (34\%). Moreover, the frequency of increased concentrations was the highest for the combination of IL-6 with CRP or IL-6 with CEA levels (88\%) and improved the diagnostic sensitivity of tumor markers-CEA with CA 19-9 (43\%) (Fig. 1). The diagnostic specificity for CRP levels (91\%) was slightly lower than for classic tumor markers $(100 \%)$, similarly as positive predictive value. However, negative predictive value was higher for IL-6 (80\%) when compared with CRP
(67\%), CA 19-9 (53\%) and CEA (49\%). The highest negative predictive value was observed for combined use of IL-6 with CRP (83\%) or CEA (84\%).

The area under the ROC curve (AUC) indicates the clinical usefulness of the proteins tested. The IL-6 area under ROC curve (0.8984) was higher than AUC for CRP (0.8075) and much higher than for CEA (0.7737) and CA 19-9 (0.7619) in the diagnosis of GC patients (Fig. 2).

\section{Discussion}

Gastric cancer (GC) is the fourth most common cancer and the second cause of cancer death in the world [22]. It shows extensive tumor invasion and early spread to metastasis sites [23]. Several serum tumor markers have been used in 
Table 3 Serum concentrations of classic tumor markers in gastric cancer patients

\begin{tabular}{|c|c|c|c|c|c|c|c|c|c|}
\hline \multirow[b]{3}{*}{ Gastric cancer patients } & \multirow{3}{*}{$\begin{array}{l}N \\
92\end{array}$} & \multicolumn{4}{|c|}{ CEA (ng/mL) } & \multicolumn{4}{|c|}{ CA $19-9(\mathrm{U} / \mathrm{mL})$} \\
\hline & & \multirow{2}{*}{$\frac{\text { Median }}{1.75^{\mathrm{a}}}$} & \multicolumn{2}{|l|}{ Range } & \multirow{2}{*}{$\frac{P}{<0.001}$} & \multirow{2}{*}{$\frac{\text { Median }}{10.23^{\mathrm{a}}}$} & \multicolumn{2}{|l|}{ Range } & \multirow{2}{*}{$\frac{P}{<0.001}$} \\
\hline & & & 0.10 & 620.00 & & & 0.00 & 50000.00 & \\
\hline Control group & 70 & 0.70 & 0.00 & 3.9 & & 2.00 & 0.00 & 24.01 & \\
\hline \multicolumn{10}{|l|}{ Tumor stage } \\
\hline II & 19 & $1.79^{\mathrm{a}}$ & 0.40 & 6.90 & \multirow[t]{3}{*}{0.286} & $5.10^{\mathrm{a}}$ & 0.00 & 54.23 & \multirow[t]{3}{*}{0.028} \\
\hline III & 27 & $1.20^{\mathrm{a}}$ & 0.30 & 120.3 & & $11.75^{\mathrm{a}, \mathrm{b}}$ & 0.00 & 1200.00 & \\
\hline IV & 46 & $1.95^{\mathrm{a}}$ & 0.10 & 620.0 & & $17.91^{\mathrm{a}, \mathrm{b}}$ & 0.00 & 50000.00 & \\
\hline \multicolumn{10}{|l|}{ Gastric wall invasion } \\
\hline $\mathrm{T} 1+\mathrm{T} 2$ & 15 & $1.79^{\mathrm{a}}$ & 0.40 & 11.89 & \multirow[t]{3}{*}{0.448} & $5.75^{\mathrm{c}}$ & 0.00 & 54.23 & \multirow[t]{3}{*}{0.081} \\
\hline $\mathrm{T} 3$ & 41 & $1.49^{\mathrm{a}}$ & 0.10 & 120.30 & & $10.06^{\mathrm{a}}$ & 0.00 & 10900 & \\
\hline $\mathrm{T} 4$ & 36 & $1.80^{\mathrm{a}}$ & 0.50 & 620.00 & & $22.23^{\mathrm{a}}$ & 0.00 & 50000 & \\
\hline \multicolumn{10}{|l|}{ Nodal metastases } \\
\hline No & 19 & $1.40^{\mathrm{a}}$ & 0.10 & 6.90 & \multirow[t]{4}{*}{0.046} & 2.33 & 0.00 & 24.17 & \multirow[t]{4}{*}{0.001} \\
\hline N1 & 12 & $1.16^{\mathrm{a}}$ & 0.56 & 40.59 & & $13.89^{\mathrm{a}, \mathrm{d}}$ & 1.27 & 723.22 & \\
\hline N2 & 22 & $1.22^{\mathrm{a}}$ & 0.30 & 82.20 & & $8.91^{\mathrm{a}}$ & 0.00 & 3262.00 & \\
\hline N3 & 39 & $2.30^{\mathrm{a}, \mathrm{d}, \mathrm{e}}$ & 0.61 & 620.00 & & $31.96^{\mathrm{a}, \mathrm{d}}$ & 0.00 & 50000.00 & \\
\hline \multicolumn{10}{|l|}{ Distant metastases } \\
\hline M0 & 53 & $1.49^{\mathrm{a}}$ & 0.30 & 120.30 & \multirow[t]{2}{*}{0.155} & $9.07^{\mathrm{a}}$ & 0.00 & 1200.00 & \multirow[t]{2}{*}{0.527} \\
\hline M1 & 39 & $2.00^{\mathrm{a}}$ & 0.10 & 620.00 & & $15.69^{\mathrm{a}}$ & 0.00 & 50000.00 & \\
\hline \multicolumn{10}{|l|}{ Resectability of tumor } \\
\hline Resectable & 72 & $1.80^{\mathrm{a}}$ & 0.10 & 620.00 & \multirow[t]{2}{*}{0.877} & $8.84^{\mathrm{a}}$ & 0.00 & 50000.00 & \multirow[t]{2}{*}{0.147} \\
\hline Nonresectable & 20 & $1.50^{\mathrm{a}}$ & 0.61 & 25.49 & & $28.18^{\mathrm{a}}$ & 0.00 & 2844.00 & \\
\hline \multicolumn{10}{|l|}{ Survival of patients } \\
\hline Alive & 50 & $1.45^{\mathrm{a}}$ & 0.1 & 82.2 & \multirow[t]{2}{*}{0.274} & $7.87^{\mathrm{a}}$ & 0.00 & 1200.00 & \multirow[t]{2}{*}{0.082} \\
\hline Died & 36 & $1.84^{\mathrm{a}}$ & 0.60 & 620.00 & & $31.94^{\mathrm{a}}$ & 0.00 & 50000.00 & \\
\hline
\end{tabular}

${ }^{a}$ Statistically significant compared to control group

b Statistically significant compared to stage II

c Statistically significant compared to T4 subgroup

${ }^{d}$ Statistically significant compared to N0 subgroup

e Statistically significant compared to N2 subgroup

${ }^{\mathrm{f}}$ Statistically significant compared to M0 subgroup

the diagnosis of GC. Some clinical investigations have demonstrated that increased levels of classic tumor markers, such as CEA and CA 19-9 correlated with clinicopathological features of GC [3, 19, 24, 25]. However, sensitivity of classic tumor markers has not proven satisfactory. Therefore, novel biochemical markers are necessary in the diagnosis of GC patients.

In the present study, we assessed concentrations of the proinflammatory cytokine-IL-6 and acute phase protein (CRP) in the sera of GC patients and compared them with classic tumor markers (CEA and CA 19-9). We demonstrated that the serum levels of IL-6 and CRP as well as classic tumor markers were significantly higher in the GC patients when compared with healthy subjects. Our findings are in agreement with a report of other authors [3, 19], who showed significantly higher concentrations of IL-6 and
CRP in GC patients in comparison with healthy subjects. In the present paper, the levels of IL-6, CRP and classic tumor markers increased with tumor stage, although statistically significant differences were found only for CRP and CA 19-9. These findings are in line with a study of Kim et al. [5], who found that serum levels of CRP significantly correlated with stage of GC. However, the authors also indicated the significant association between serum IL-6 concentrations and TNM stage $[5,19]$. The opposite results were shown in a study of Ilhan et al. [3], who failed to establish any significant differences between serum CRP levels and tumor stage.

In addition, in the current study, serum concentrations of IL-6, CRP and CA 19-9 increased with the gastric wall invasion ( $\mathrm{T}$ factor). The differences were significant only for CRP and CA 19-9. Similar results were obtained by 
Table 4 Results of Cox's univariate analysis in gastric cancer patients

\begin{tabular}{lll}
\hline & Odds ratio & $P$ value \\
\hline Tumor stage & & $0.001^{\mathrm{a}}$ \\
TNM III versus TNM II & 1.812 & 0.419 \\
TNM IV versus TNM II & 7.827 & $0.001^{\mathrm{a}}$ \\
Tumor size (T factor) & & $0.003^{\mathrm{a}}$ \\
T3 versus 2 & 1.456 & 0.529 \\
T4 versus 2 & 4.393 & $0.008^{\mathrm{a}}$ \\
N & & $0.001^{\mathrm{a}}$ \\
N1 versus N0 & 0.776 & 0.826 \\
N2 versus N0 & 2.855 & 0.131 \\
N3 versus N0 & 8.437 & $0.001^{\mathrm{a}}$ \\
M & 7.615 & $0.001^{\mathrm{a}}$ \\
Resectability & 0.203 & $0.001^{\mathrm{a}}$ \\
CEA & 1.008 & $0.005^{\mathrm{a}}$ \\
CA19-9 & 1.000 & $0.005^{\mathrm{a}}$ \\
CRP & 1.008 & 0.061 \\
IL-6 & 1.013 & 0.238 \\
\hline
\end{tabular}

a Statistically significant when $P<0.05$

Kim et al. [5]; however, the authors also found the significant correlations between serum IL-6 levels and tumor size. It has been suggested that in GC patients serum IL-6 and CRP may reveal the degree of damage of gastric wall caused by ulcerative reaction of the tumor.
Serum levels of all the proteins tested varied according to nodal metastases ( $\mathrm{N}$ factor) and the CRP, IL- 6 and CEA concentrations were correlated with the presence of lymph node metastasis. Our results are in agreement with findings of Kim et al. [5], who revealed significant differences in lymph node metastasis and serum concentrations of CRP as well as IL-6. Opposite findings were established by Ikeguchi et al. [19], who found no significant correlation between serum IL-6 level and lymph node metastasis in GC patients. Cancer invasion begins with inflammation around the tumor cells [5]; therefore, CRP and IL-6 levels might be higher in the sera of patients with invasive cancer than those in noninvasive tumors. In addition, in the present paper, the serum concentrations of all the proteins tested correlated with the presence of distant metastasis (M factor); however, the differences between M0 and M1 subgroups were found to be significant only for CRP levels. Opposite to our paper, the study of Thong-Ngam et al. [26] have indicated that the IL-6 levels in GC patients with distant metastasis were significantly higher than in those without metastasis. These findings have been attributed to a host mechanism, including IL-6 autocrine and paracrine pathway [5, 10, 13, 14]. IL-6 released from leukocytes is able to activate the production of IL-6 by tumor cells with the IL-6 receptor as well as stimulated stromal cells promoted the secretion of molecules, such as VEGF $[3,11,27]$. It has been proven that when concentrations of IL-6 increased, CRP levels also increased, thus CRP has

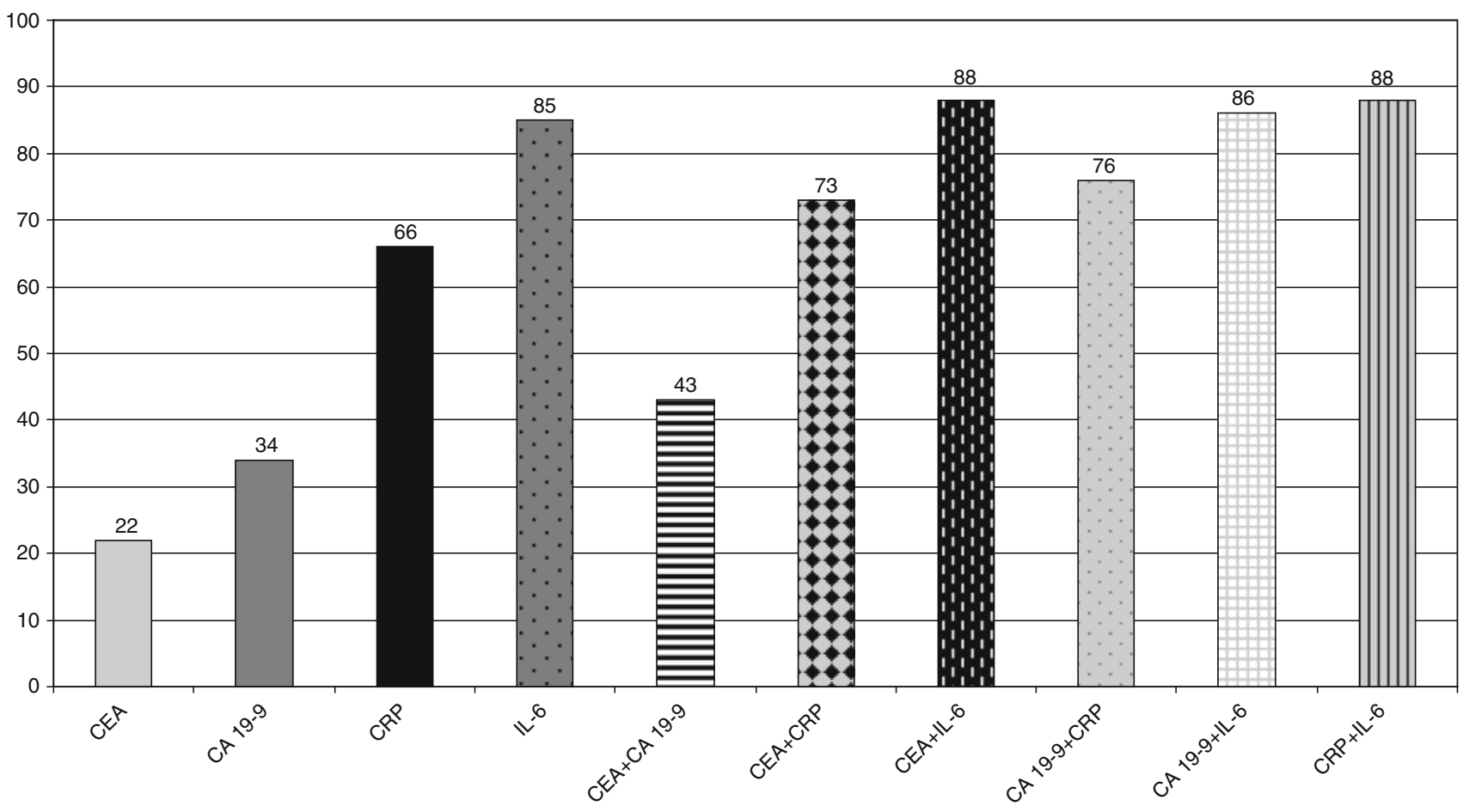

Fig. 1 Percentage of increased concentrations (diagnostic sensitivity) of IL-6, CRP and tumor markers in gastric cancer patients 


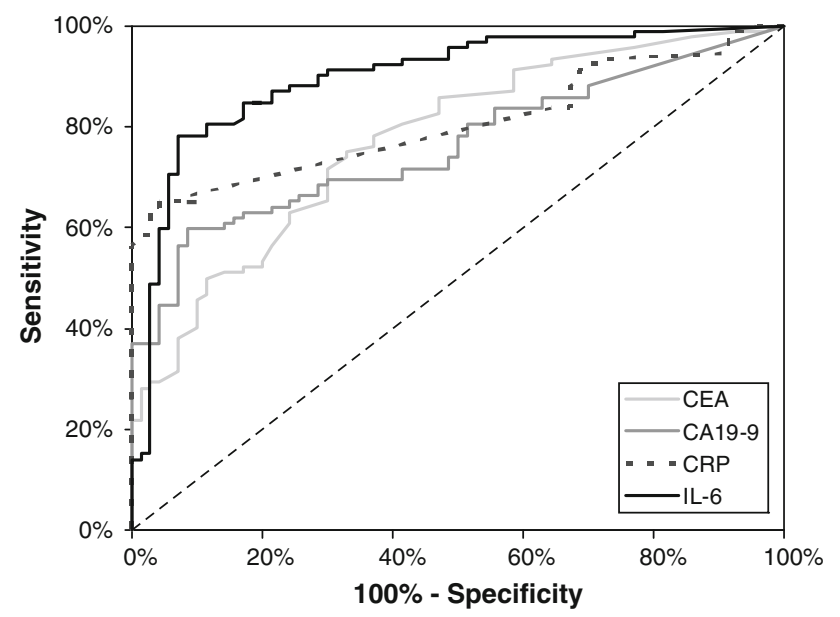

Fig. 2 Areas under ROC curves for IL-6 (AUC $=0.8984$, $P<0.001$ ), CRP (AUC $=0.8075, P<0.001$ ) and tumor markersCEA $(\mathrm{AUC}=0.7737, P<0.001)$ and CA 19-9 $(\mathrm{AUC}=0.7619$, $P<0.001)$ in gastric cancer patients

generally been connected with IL-6 and indirectly with cancer progression [5].

Moreover, we revealed that the concentrations of IL-6, CRP and CA 19-9 were significantly higher in patients with nonresectable tumor in comparison with the resectable cancer group. Similar results were observed previously in patients with colorectal cancer (CRC), although the differences in IL-6 and CRP concentrations between the group of patients with resectable tumor and subjects with nonresectable CRC were statistically significant [17].

We observed that the concentrations of IL-6, CRP and classic tumor markers were higher in the sera of patients who died of GC when compared with patients who survived. In agreement with present study, previously we indicated the higher concentrations of both proinflammatory proteins in patients who died because of CRC in comparison with those who survived and these differences were significant [17]. We also assessed the relationship between the survival of GC patients and the serum concentrations of the proteins tested using the Kaplan-Meier method, although we did not detect any tendency that would point to IL-6 and CRP as prognostic factors for GC patients' survival. Our observations are in the line with the findings of Wu et al. [7], who indicated that serum levels of IL-6 correlated with patients' survival, but not as an independent prognostic factor. Similarly, Ikeguchi et al. [19] revealed that even though there was a significant difference in survival between patients with high levels of serum IL-6 and those with low levels, serum IL-6 concentrations were not independent on tumor stage.

In the present study, we evaluated the diagnostic criteria, such as the diagnostic sensitivity and specificity, positive and negative predictive value as well as ROC curve for all proteins tested. The percentage of increased concentrations and negative predictive value of IL- 6 was higher than those of CRP and classic tumor markers and increased for the combined use of IL-6 with CRP or CEA. The diagnostic specificity for CRP levels was slightly lower than for classic tumor markers, similarly as positive predictive value. The percentage of increased concentrations of IL-6 (85\%) established in current paper was higher to those obtained in previous studies, where we assessed the diagnostic sensitivity of other biomarkers in GC patients, including matrix metalloproteinase 9 (MMP-9) (60\%) and its tissue inhibitor (TIMP-1) (78\%) as well as hematopoietic growth factors (HGFs), such as granulocyte colony-stimulating factor (G-CSF) (36\%), granulocyte macrophage colonystimulating factor (GM-CSF) (29\%), stem cell factor (SCF) (19\%) and macrophage colony-stimulating factor (M-CSF) (10\%) [24, 25]. However, the diagnostic specificity for CRP (91\%) was slightly lower than for M-CSF (95\%), SCF (94\%) and G-CSF (92\%), but higher than for GM-CSF (82\%) [25].

In addition, we showed that the IL-6 area under ROC curve was higher than AUC for CRP and both classic tumor markers. Current results of AUC for all proteins tested are similar to those obtained in our previous study concerning diagnostic usefulness of IL-6, CRP and classic tumor markers in CRC patients [17] where we also showed that AUC for IL-6 (0.8984) was higher than for CRP, CA 19-9 and CEA. Moreover, in the present study, the area under ROC curve of IL- 6 and CRP was higher than those of other biomarkers of GC from our previous study, such as: G-CSF (0.77), GM-CSF (0.70), SCF (0.62), M-CSF (0.53) as well as MMP-9 (0.7141), but the AUC for TIMP$1(0.8320)$ was lower than IL-6 and higher than for CRP $[24,25]$.

According to our knowledge, the present study is the first to compare the diagnostic criteria of IL-6 and CRP with classic tumor markers, CEA and CA 19-9 in the sera of GC patients. The percentage of increased concentrations and the most important diagnostic criterion, area under ROC curve, was the highest for IL-6 among biomarkers tested (CRP, CEA and CA 19-9). In addition, we assessed the serum IL-6, CRP and classic tumor markers concentrations in GC patients in relation to clinicopathological features of tumor. We found that serum levels of all the proteins were significantly higher in GC patients than in healthy subjects. Moreover, concentrations of IL-6, CEA and CA 19-9 correlated with nodal metastasis, whereas CRP with tumor stage, tumor size, presence of nodal and distant metastases. Neither the proinflammatory proteins, IL-6 and CRP nor tumor markers were found to be independent prognostic factors for patients' survival. In conclusion, our findings suggest higher usefulness of serum IL-6 and CRP than classic tumor markers, CEA and CA 19-9 in the diagnosis of GC. However, general inflammatory state is 
common to other epithelial tumors, such as pancreatic [28] or colorectal cancer [17], where the concentrations of IL-6 and CRP increased in the line with the progress of tumor disease. Therefore, further investigations are necessary.

\section{Conflict of interest None.}

Open Access This article is distributed under the terms of the Creative Commons Attribution Noncommercial License which permits any noncommercial use, distribution, and reproduction in any medium, provided the original author(s) and source are credited.

\section{References}

1. Parkin DM, Bray F, Ferlay J, Pisani P (2002) Global cancer statistics, 2002. CA Cancer J Clin 55:74-108

2. Lochhead P, El-Omar EM (2008) Gastric cancer. Br Med Bull 85:87-100

3. Ilhan N, Ilhan Y, Akbulut H, Kucuksu M (2004) C-reactive protein, procalcitonin, interleukin- 6 , vascular endothelial growth factor and oxidative metabolites in diagnosis of infection and staging in patients with gastric cancer. World J Gastroenterol 10:1115-1120

4. Hussain SP, Harris CC (2007) Inflammation and cancer: an ancient link with novel potentials. Int J Cancer 121:2373-2380

5. Kim DK, Oh SY, Kwon HC, Lee S, Kwon KA, Kim BG, Kim SG, Kim SH, Jang JS, Kim MC, Kim KH, Han JY, Kim HJ (2009) Clinical significances of preoperative serum interleukin-6 and C-reactive protein level in operable gastric cancer. BMC Cancer 9:155

6. Kai H, Kitadai Y, Kodama M, Cho S, Kuroda T, Ito M, Tanaka S, Ohmoto Y, Chayama K (2005) Involvement of proinflammatory cytokines IL-1beta and IL-6 in progression of human gastric carcinoma. Anticancer Res 25:709-713

7. Wu CW, Wang SR, Chao MF, Wu TC, Lui WY, P'eng FK, Chi CW (1996) Serum interleukin-6 levels reflect disease status of gastric cancer. Am J Gastroenterol 91:1417-1422

8. Heikkilä K, Ebrahim S, Lawlor DA (2008) Systematic review of the association between circulating interleukin-6 (IL-6) and cancer. Eur J Cancer 44:937-945

9. Wang CS, Sun CF (2009) C-reactive protein and malignancy: clinico-pathological association and therapeutic implication. Chang Gung Med J 32:471-482

10. Matsuo K, Oka M, Murase K, Soda H, Isomoto H, Takeshima F, Mizuta Y, Murata I, Kohno S (2003) Expression of interleukin 6 and its receptor in human gastric and colorectal cancers. J Int Med Res 31:69-75

11. Huang SP, Wu MS, Wang HP, Yang CS, Kuo ML, Lin JT (2002) Correlation between serum levels of interleukin-6 and vascular endothelial growth factor in gastric carcinoma. J Gastroenterol Hepatol 17:1165-1169

12. Lin MT, Lin BR, Chang CC, Chu CY, Su HJ, Chen ST, Jeng YM, Kuo ML (2007) IL-6 induces AGS gastric cancer cell invasion via activation of the $\mathrm{c}-\mathrm{Src} / \mathrm{RhoA} / \mathrm{ROCK}$ signaling pathway. Int $\mathrm{J}$ Cancer 120:2600-2608

13. Ito R, Yasui W, Kuniyasu H, Yokozaki H, Tahara E (1987) Expression of interleukin-6 and its effect on the cell growth of gastric carcinoma cell lines. Jpn J Cancer Res 88:953-958
14. Lee SA, Choi SR, Jang JS, Lee JH, Roh MH, Kim SO, Kim MC, Kim SJ, Jeong JS (2010) Expression of VEGF, EGFR, and IL-6 in gastric adenomas and adenocarcinomas by endoscopic submucosal dissection. Dig Dis Sci 55:1955-1963

15. Liao WC, Lin JT, Wu CY, Huang SP, Lin MT, Wu AS, Huang YJ, Wu MS (2008) Serum interleukin-6 level but not genotype predicts survival after resection in stages II and III gastric carcinoma. Clin Cancer Res 14:428-434

16. Kallio R, Surcel HM, Bloigu A, Syrjälä H (2000) C-reactive protein, procalcitonin and interleukin- 8 in the primary diagnosis of infections in cancer patients. Eur J Cancer 36:889-894

17. Groblewska M, Mroczko B, Wereszczyńska-Siemiątkowska U, Kędra B, Łukaszewicz M, Baniukiewicz A, Szmitkowski M (2008) Serum interleukin 6 (IL-6) and C-reactive protein (CRP) levels in colorectal adenoma and cancer patients. Clin Chem Lab Med 46:1423-1428

18. Hara M, Matsuzaki Y, Shimuzu T, Tomita M, Ayabe T, Enomoto Y, Onitsuka T (2007) Preoperative serum C-reactive protein level in non-small cell lung cancer. Anticancer Res 27:3001-3004

19. Ikeguchi M, Hatada T, Yamamoto M, Miyake T, Matsunaga T, Fukumoto Y, Yamada Y, Fukuda K, Saito H, Tatebe S (2009) Serum interleukin-6 and -10 levels in patients with gastric cancer. Gastric Cancer 12:95-100

20. Jang JS, Choi SR, Han SY, Roh MH, Lee JH, Lee SW, Jeung JS, Kim MC, Son YK, Baek YH (2009) Predictive significance of serum IL-6, VEGF, and CRP in gastric adenoma and mucosal carcinoma before endoscopic submucosal dissection. Korean $\mathrm{J}$ Gastroenterol 54:99-107

21. Jass JR, Sobin LH (1989) WHO international histological classification of tumors. Springer-Verlag, Histological typing of intestinal tumors. New York

22. Brenner H, Rothenbacher D, Arndt V (2009) Epidemiology of stomach cancer. Methods Mol Biol 472:467

23. Shim KN, Jung SA, Joo YH, Yoo K (2007) Clinical significance of tissue levels of matrix metalloproteinases and tissue inhibitors of metalloproteinases in gastric cancer. J Gastroenterol 42:120-128

24. Mroczko B, Groblewska M, Łukaszewicz-Zajac M, Bandurski R, Kedra B, Szmitkowski M (2009) Pre-treatment serum and plasma levels of matrix metalloproteinase 9 (MMP-9) and tissue inhibitor of matrix metalloproteinases 1 (TIMP-1) in gastric cancer patients. Clin Chem Lab Med 47:1133-1139

25. Mroczko B, Wereszczynska-Siemiatkowska U, Groblewska M, Lukaszewicz M, Szmitkowski M, Gryko M, Kedra B (2006) The diagnostic value of hematopoietic cytokines measurement in the sera of gastric cancer and gastric ulcer patients. Clin Chim Acta 374:165-167

26. Thong-Ngam D, Tangkijvanich $\mathrm{P}$, Lerknimitr R, Mahachai V, Theamboonlers A, Poovorawan Y (2006) Diagnostic role of serum interleukin-18 in gastric cancer patients. World J Gastroenterol 12:4473-4477

27. Ashizawa T, Okada R, Suzuki Y, Takagi M, Yamazaki T, Sumi T, Aoki T, Ohnuma S, Aoki T (2005) Clinical significance of interleukin-6 (IL-6) in the spread of gastric cancer: role of IL-6 as a prognostic factor. Gastric Cancer 8:124-131

28. Mroczko B, Groblewska M, Gryko M, Kędra B, Szmitkowski M (2010) Diagnostic usefulness of serum interleukin 6 (IL-6) and Creactive protein $(\mathrm{CRP})$ in the differentiation between pancreatic cancer and chronic pancreatitis. J Clin Lab Anal 24:265-271 